\title{
Serum biomarkers analyzed by LC-MS/MS as predictors for short outcome of non-small cell lung cancer patients treated with chemoradiotherapy
}

\author{
W. HUANG ${ }^{\ddagger}$ X. DING ${ }^{\ddagger}$, B. LI* , M. FAN, T. ZHOU, H. SUN, Y. YI, J. ZHANG
}

Department of Radiation Oncology, Shandong Cancer Hospital, Shandong Academy of Medical Sciences, Shandong's Key Laboratory of Radiation Oncology, Jinan, P.R. China

${ }^{*}$ Correspondence: baoshli@yahoo.com

${ }^{*}$ Contributed equally to this work.

Received February 16, 2012 / Accepted May 18, 2012

\begin{abstract}
Purpose: To find potential serum biomakers that can predict clinical outcome upon treatment in non-small cell lung cancer (NSCLC) by analyzing differential proteins in serum with different sensitivity of chemoradiotherapy (CRT).

Materials and Methods: Sera were collected from 37 NSCLC patients before they were treated with concurrent cisplatinbased CRT. According to the outcome of CRT, the patients were divided into sensitive group and resistant one. The proteins in sera were separated by two-dimensional gel electrophoresis after the high abundance proteins were removed from sera. The significantly differentially expressed proteins between two groups were analyzed by liquid chromatography and tendem mass spectrometry (LC-MS/MS). Then, an additional 50 serum samples were used for ELISA analysis to validate the identified proteins that we got in the experiment.

Results: Proteins in sera of each group were successfully separated on 2D gels. There were significant discrepancies in serum protein expression between NSCLC patients with different CRT sensitivity. Among eight differently expressed proteins, six proteins were successfully identified with five of which higher expressed and one lower expressed in resistant group. The increased Alpha-1-antitrypsin ( $\alpha 1-\mathrm{AT})$ level in resistant group comparing to sensitive one were validated by ELISA analysis $(p<0.05)$.

Conclusions: Proteomic approach may serve as a useful method in detecting the potential biomarkers for predicting the outcome of treatment in NSCLC patients. NSCLC patients with high a1-AT level in serum before CRT may have a worse treatment outcome.
\end{abstract}

Key words: chemoradiotherapy, non-small cell lung cancer, biomarkers, proteomics

Lung cancer is the leading cause of cancer death in the world, and $80-85 \%$ of lung cancer cases are classified as non-small cell lung cancer (NSCLC)[1]. Standard treatment for NSCLC involves platinum-based combination chemotherapy with concurrent radiotherapy which could improve survival for some patients. However, only a minority of patients respond to the chemoradiotherapy (CRT) at the cost of substantial toxicity for all treated patients[2]. There is an urgent need for methods to predict outcome in order to select patients who are likely to benefit from treatment. Oncologists have attempted to identify clinical, functional imaging and molecular markers that may help clinicians and researchers distinguish the subgroup of CRT resistant NSCLC patients. However, few factors have been widely ac- cepted as useful predictive markers for an individual patient undergoing CRT.

Secreted proteins derived from cancer tissues in blood may be the potential serologic biomarkers of cancer. However, serum proteins are difficult to be analyzed as potential biomarkers because of their complexity and dynamic range, which spans ten orders of magnitude. Also, abundant serum proteins, such as albumin, IgG and transferrin mask many of the low abundant proteins that represent putative biomarkers. It is necessary to globally analyze the secreted proteins that would provide new clues to identify potential serologic biomarkers of lung cancer. Proteomics is a relatively new approach for analysis of complex biological specimens, including serum[3], urine[4] and tissue[5]. Mass spectrom- 
etry (MS) has shown promise in biomarker discovery, it will potentially benefit the patients from such therapies.

We hypothesized that specific serum biomarkers could predict clinical outcome of patients who underwent CRT. Data analyses of serum peptide profiles between subgroups of patients with different CRT sensitivity were conducted. The goal was to identify potential serum biomarkers that can predict the outcome of NSCLC patients treated with standard CRT.

\section{Patients and methods}

Patients and CRT. Pre-treatment serum samples were collected from 37 patients with stage IIIB or IV NSCLC between September 2009 and March 2011 at the Shandong Cancer Hospital, Jinan, China. Studies were performed after obtaining patient consent and under protocols approved by the institutional review board. Patient characteristics were listed in Table 1 . All patients were treated with cisplatin-based combination chemotherapy and concurrent radiotherapy. Radiation therapy was delivered up to a total dose of 62.4 to 68.0 Gy using intensity-modulated radiation therapy or conformal radiation therapy technique. Clinical endpoints used to establish these signatures were response to treatment according to the Response Evaluation Criteria in Solid Tumors (RECIST) criteria at 4 weeks after treatment. Patients with outcome of a complete response (CR) or a partial response (PR) were subsequently classified as sensitive group. However, those who got an outcome of

Table 1. Clinicopathological features of 37 patients with NSCLC

\begin{tabular}{|c|c|}
\hline Characteristics & Number of cases (\%) \\
\hline $\operatorname{Age}(y)$ & $56.0 \pm 7.5$ \\
\hline \multicolumn{2}{|l|}{ Sex } \\
\hline male & $24(64.8)$ \\
\hline female & $13(35.2)$ \\
\hline \multicolumn{2}{|l|}{ Stage } \\
\hline IIIA & $9(24.3)$ \\
\hline IIIB & $23(62.2)$ \\
\hline IV & $5(13.5)$ \\
\hline \multicolumn{2}{|l|}{ Pathologic type } \\
\hline Adenocarcinoma & $14(37.8)$ \\
\hline Squamous cell carcinoma & $20(54.1)$ \\
\hline other & $3(8.1)$ \\
\hline \multicolumn{2}{|l|}{ Chemotherapy } \\
\hline cisplatin/gemcitabine & $13(35.2)$ \\
\hline cisplatin/docetaxel & $9(24.3)$ \\
\hline cisplatin/vinorelbine & $9(24.3)$ \\
\hline cisplatin/pemetrexed & $6(16.2)$ \\
\hline \multicolumn{2}{|l|}{ RECIST } \\
\hline complete response & $6(16.2)$ \\
\hline partial response & $18(48.7)$ \\
\hline stable disease & $11(29.7)$ \\
\hline progressive disease & $2(5.4)$ \\
\hline
\end{tabular}

stable disease $(\mathrm{SD})$ or progressive disease $(\mathrm{PD})$ were defined as resistant group.

Serum samples. Serum samples were collected by venipuncture and 5 milliliters of whole blood were collected from NSCLC patients before CRT. Venous blood samples were taken in the morning's fasting state, then centrifuged at $20^{\circ} \mathrm{C}$ for $10 \mathrm{~min}$ at $1,500 \mathrm{~g}$ between half an hour to two hours. The sera were stored in plastic vials at $-80^{\circ} \mathrm{C}$ until the consecutive analyses. Abundant serum proteins such as albumin, IgG, IgA, and transferrin were removed with Aurum Serum Protein Kit (Bio-Rad, USA).

Two-dimensional electrophoresis (2-DE). $350 \mu \mathrm{l}$ mixed serum samples of sensitive and resistant groups underwent 2 -DE, and each experiment was repeated 3 times. Isoelectric focusing electrophoresis (IEF) was performed using IPGstrip (pH 3-10L) on IPGphor isoelectric focusing cell (Amersham pharmacia Biotech, Sweden). Second-dimension SDS-PAGE (Bio-Rad, USA) was conducted as described by manufacturer and Görg[6]. After electrophoresis, the protein spots were visualized by silver-based staining technique with the protein silver stain kit (Amersham pharmacia Biotech, Sweden).

Image analysis. The 2-DE images were captured using ImageScanner (Amersham Pharmacia Biotech, Sweden). Spot detection, quantification and alignment were performed with the ImageMaster 2D Elite 4.01 software (Amersham Pharmacia Biotech, Sweden). Intensity of each spot was quantified by calculation spot volume after normalization of the image using the total spot volume normalization method multiplied by the total area of all the spots. The reproducibility of spot position was calculated with Gorbett's method[7]. Molecular mass weight and pI values were determined according to standard protein markers covering the range of $10-100 \mathrm{KDa}$ and the immobilized $\mathrm{pH}$ gradient strips. Statistical analysis was carried out with SPSS for Windows 13.0 and Excel.

LC-MS/MS analysis. The differentially expressed protein patterns in the CBB staining were the same as that of of 2 DE gel visualized by silver-based staining. The protein band containing the desired biomarker was cut by from the gel and subjected to overnight tryptic digestion. The selected protein spots were identified by LC-MS/MS using a nanoliquid chromatography-electrospray ionization-tendem mass spectrometry (nano-LC-ESI-MS/MS) system consisting of an nanoAquity UPLC system (Waters, USA) and Synapt High Definition Mass Spectrometry (Waters, USA) equipped with a nano-ESI source. The peptide solutions were loaded to a C18 trap column (nanoACQUITY) $(180 \mu \mathrm{m} \times 20 \mathrm{~mm} \times 5 \mu \mathrm{m}$ (symmetry)). The flow rate was $15 \mu \mathrm{l} / \mathrm{min}$. Then the desalted peptides were analyzed by $\mathrm{C} 18$ analytical column (nanoACQUITY) $(75 \mu \mathrm{m} \times 250 \mathrm{~mm} \times 1.7 \mu \mathrm{m}$ (symmetry) $)$ at a flow rate of $200 \mathrm{nl} / \mathrm{min}$. The solutions used as the mobile phases were (A) $\mathrm{H}_{2} \mathrm{O}$ and (B) $\mathrm{ACN}$, and both contained $0.1 \% \mathrm{v} / \mathrm{v}$ formic acid. The flow rate was maintained at $200 \mathrm{~nL} / \mathrm{min}$. The gradient was started at $5 \% \mathrm{~B}$, reached $40 \% \mathrm{~B}$ in $65 \mathrm{~min}, 85 \% \mathrm{~B}$ in the next 10 
min, and $100 \% \mathrm{~A}$ in the final $10 \mathrm{~min}$. Data-dependent acquisition mode (m/z 50-2000) was enabled, and each survey MS scan was followed by five MS/MS scans with the 30s dynamic exclusion option on. The nanospray parameters were 2500 $\mathrm{V}$ for capillary voltage, $35 \mathrm{~V}$ for cone voltage, $90^{\circ} \mathrm{C}$ for source temperature, and 15 psi collision gas back pressure.

Bioinformatics analysis. All mass spectra were used to search the Swiss-Prot database with the Mascot search engine (www.matrixscience.com). The searching parameter was set up as follows: the taxonomy was selected as homo sapiens; the peptide mass tolerance was $1.0 \mathrm{Da}$; the MS/MS tolerance was $0.5 \mathrm{Da}$; the missed cleavage sites were allowed up to 1 ; the fixed modifications were selected as carbamidomethyl (cysteine); the variable modification was selected as oxidation (methionine) or none. The data on 2-DE images of intergroup and intragroup were analyzed by SPSS (version 16.0) using $\chi^{2}$ tests and $p$-values less than 0.05 were considered statistically significant.

ELISA Analysis. To validate the effect of Alpha-1-antitrypsin (a1-AT) and Apolipoprotein A-1 (ApoA-1) in sera from NSCLC patients before CRT, an additional 50 serum samples were applied for ELISA analysis, 37 from sensitive group with an age range of 38-73 years (median, 56 years), 13 from resistant group with an age range of 29-78 years (median, 51 years). We strictly detected the level of $\alpha 1$-AT and ApoA-1 in sera by ELISA with Human a1-AT /ApoA1 ELISA Kit according to the manufacturer's instructions (Rapidbio, USA). Read the optical concentration (O.D.) at $450 \mathrm{~nm}$ using a microtiter plate reader within 30 minutes. All samples were assayed in triplicate and the results were the mean values of the reading. For each serum sample, O.D. value of the fusion partner GST was subtracted from O.D. value of the fusion protein. The cutoff value of reactivity was defined as mean O.D. of sample plus 3 folds of standard deviations (SD) of normal sera.

\section{Results}

Tumor Response. At 4 weeks after chemotherapy and radiotherapy, those who achieved a $\mathrm{CR} / \mathrm{PR}$ or a $\mathrm{PD} / \mathrm{SD}$ were deemed as sensitive group or resistant group respectively on CT assessment by RECIST criteria. Twenty-four patients (6 patients attained CR and 18 had PR) were assessable for response and the overall response rate was $64.9 \%$. In contrast, 11 patients achieved SD and only 2 patients attainted PD.

Analysis of the 2-DE image. In order to measure the reproducibility, 2-DE for the sensitive group and resistant group was repeated three times, respectively. The image analyses showed that these 2-DE maps were reproducible. Protein spots in sensitive and resistant group were $825 \pm 64$ and $845 \pm 48$, respectively. Comparison of 2-DE images between sensitive and resistant group revealed significant difference $\left(\chi^{2}=1.483, P=0.032\right)$. A total of 78 well-resolved and matched spots among three tumor-gels were chosen randomly to calculate the deviation of the spot position. (Fig. 1)

Analysis of the differential protein-spots. The differential protein-spots between sensitive and resistant group were detected by 2 -DE gel image analyses software. Eight differential protein-spots (seven spots higher expressed and one spot lower expressed in resistant group, Fig. 2) were detected by methods of computer software combined with manually operation.

Identification of specific protein spots. The resulting protein was determined by comprehensively considering the corresponding experimental $\mathrm{pI}, \mathrm{Mr}$, the number of matched peptides, and expression level (Fig. 3). Among eight differently expressed protein spots, six differentially expressed proteins were successfully identified, five of which higher expressed and one lower expressed in resistant group (Table 2).

Serum levels of a1-AT and APOP-1. As shown in Fig. 4, the concentration of ApoA-1 before CRT in sensitive and resistant group were $(852.81 \pm 371.31) \mathrm{ng} / \mathrm{ml}$ and $(692.25 \pm 299.26) \mathrm{ng} / \mathrm{ml}$, respectively $(p>0.05)$. However, the concentration of $\alpha 1$-AT before CRT was (282.94 $\pm .143 .88)$ $\mathrm{ng} / \mathrm{ml}$ in sensitive group and $(400.36 \pm 152.26) \mathrm{ng} / \mathrm{ml}$ in resistant group $(p=0.016)$.

\section{Discussion}

This study was prompted by the desire to discover serum biomarker/protein in samples from NSCLC patients that can predict the outcome of CRT. Biomarker discovery has primarily been focused on diagnostic biomarkers, while less attention has been given to predictive biomarkers of therapy

Table 2. Differential serum proteins between sensitive and resistant group identified by LS-MS/MS

\begin{tabular}{|c|c|c|c|c|c|}
\hline Spot No. & Protein name & ID & $\mathrm{Mr}$ & $\mathrm{pI}$ & $\begin{array}{l}\text { Expression level } \\
\text { in resistive group }\end{array}$ \\
\hline 1 & POTE ankyrin domain family member E (POTEE) & Q6S8J3 & & 5.83 & $\uparrow$ \\
\hline 2 & Transmembrane and coiled-coil domain-containing protein 5B (TMC5B) & A8MYB1 & 35741 & 4.98 & $\uparrow$ \\
\hline 2 & Gamma-taxilin (TXLNG) & Q9NUQ3 & 60548 & 7.23 & $\uparrow$ \\
\hline 5 & Alpha-1-antitrypsin (a1-AT) & Q96BF9 & 46707 & 5.37 & $\uparrow$ \\
\hline 7 & Glial fibrillary acidic protein (GFAP) & P14136 & 49850 & 5.42 & $\uparrow$ \\
\hline 8 & Apolipoprotein A-1 (ApoA1) & P02647 & 30759 & 5.56 & $\downarrow$ \\
\hline
\end{tabular}




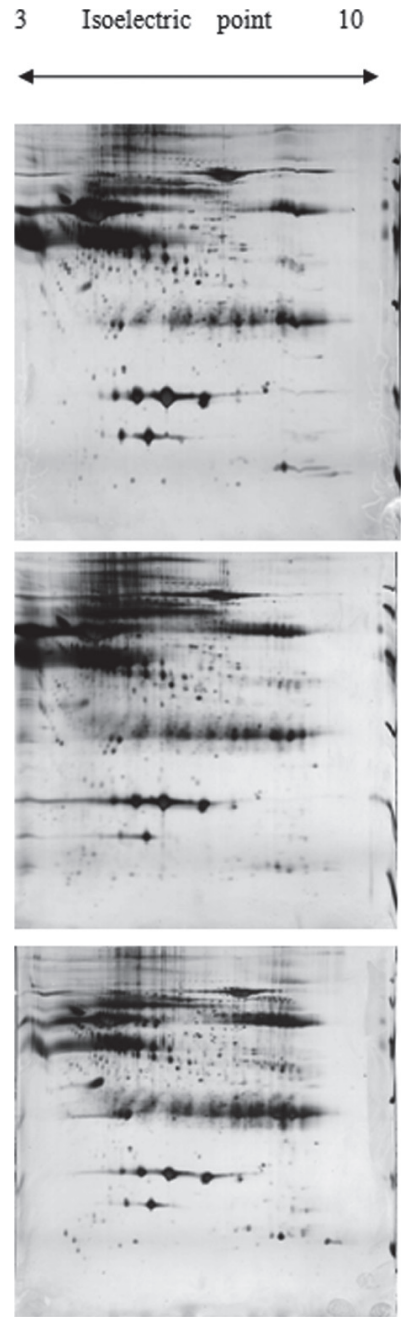

A. Sensitive group
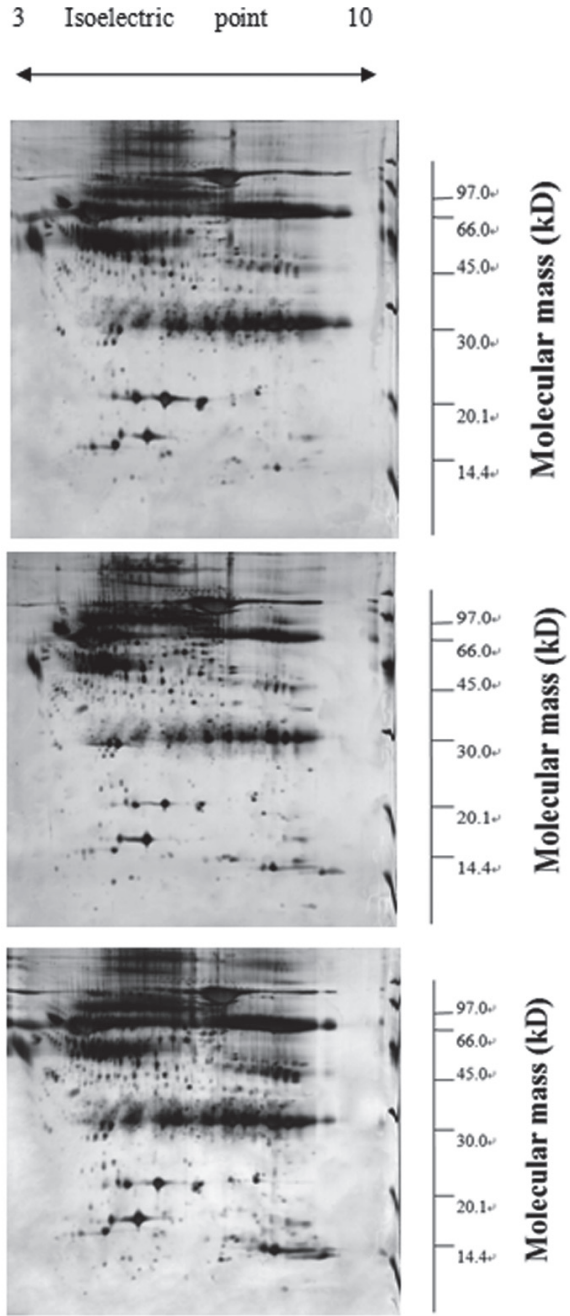

B. Resistant group

Figure 1. Two dimensional electrophoretic map of sensitive and resistant group
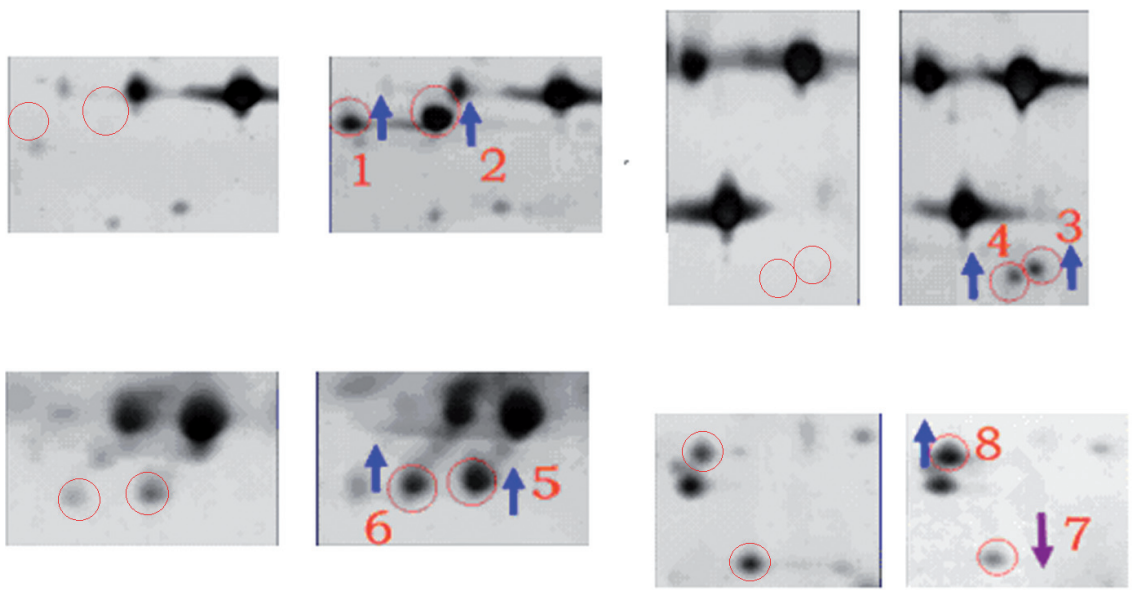

A. Sensitive group

A. Sensitive group

B. Resistant group

Figure 2. Differential expression of protein spots over expressed and lower expressed in resistant group 


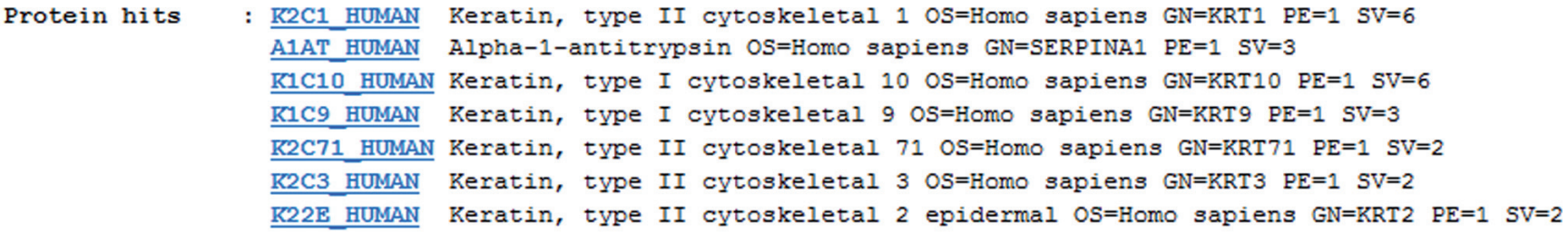

\section{Probability Based Mowse Score}

Ions score is $-10 * \log (\mathrm{P})$, where $\mathrm{P}$ is the probability that the observed match is a random event. Individual ions scores $>30$ indicate identity or extensive homology $(p<0.05)$.

Protein scores are derived from ions scores as a non-probabilistic basis for ranking protein hits.

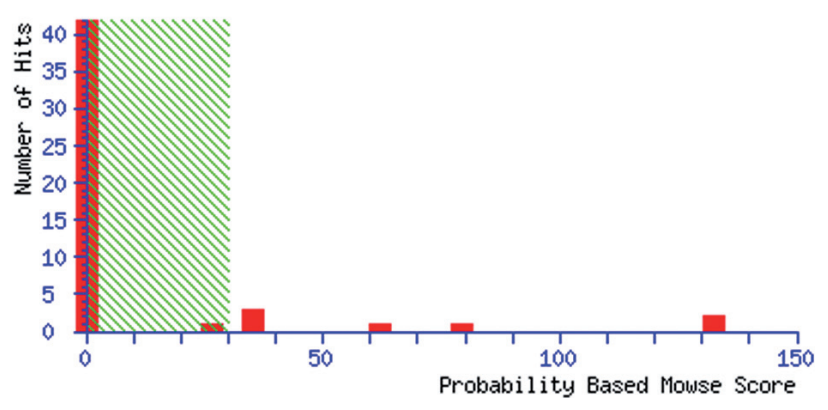

Figure 3. LC-MS/MS analysis of spot 5

response. One limitation of nearly all anti-cancer therapies is that most exhibits clinical activity in only a subset of patients. The successful development of any drug should be linked to predictors of its efficacy, as these biomarkers would considerably increase the likelihood that an individual patient will benefit. Given the financial and societal costs of treating unselected patients with CRT, the predictive biomarker could be tremendously valuable, thus it is imperative to endeavor to identify biomarkers predictive of treatment benefit. Large number of proteins present in the most important body fluid and serum are useful biomarkers of irregular or pathological conditions (i.e., tumors, modified immune responses, or vascular disease), as these proteins are often differentially expressed in abnormal and normal conditions. Proteomic analyses of serum proteins have been discussed for more than 10 years because serum biomarkers can be analyzed relatively noninvasively, and it continues to be a topic of intensive investigations. There are several advantages to the serum MS profiling described here, especially compared with more labor intensive and technically challenging assays, such as immunohistochemistry, fluorescence in situ hybridization, and PCR, due to the unavailability of high-quality tumor specimens and intratumoral heterogeneity $[8,9]$. LC-MS/MS has shown promise in biomarker discovery and proved to be a useful method for detection of low abundance proteins[10], potentially allowing the selection of patients who may benefit from such therapies. Early studies using MS to develop proteomic profiles from patient serum, coupled with advanced

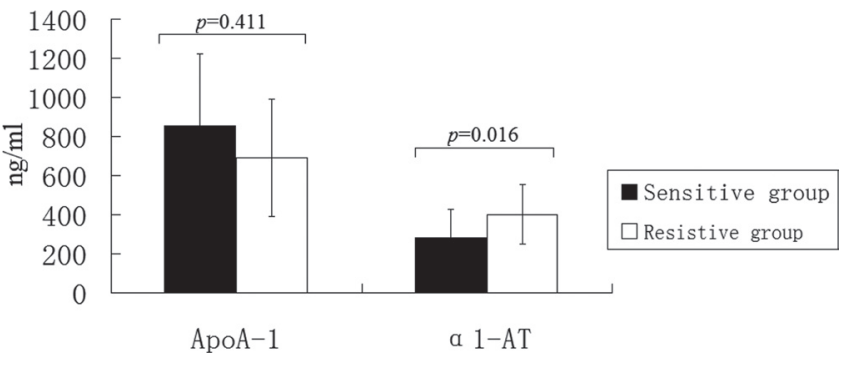

Fig 4. The statistical analysis of the concentration of the a1-AT and ApoA-1 in Sera (Independent Samples Test)

data mining algorithms had triggered hopes that this technology could be used for cancer diagnosis, prognosis, and disease/treatment monitoring. In a study by Stuart Salmon et al, a predictive MALDI-TOF-MS-based proteomic algorithm for "good" or "poor" clinical outcome upon epidermal growth factor tyrosine kinase inhibitor (EGFR-TKI) therapy was established[11]. However, in that study none of the peptides corresponding to the classifying $\mathrm{m} / \mathrm{z}$ features were identified.

This study was exploratory based on the hypothesis that serum protein may reliably predict the outcome of patients treated with cisplatin-based CRT. To avoid systematic or procedural bias in our study, the positions on the plates were randomized, and the sample spectrometry 
was replicated a total of three times and on several days. Six differential proteins were identified by LC-MS/MS coupled to bioinformatics pattern discovery to predict treatment outcome, including five proteins having higher expression and the other one lower expression in patients with resistant tumor. Some of the identified proteins with differential expression are structural proteins (TMC5B and GFAP), and others are regulatory proteins of cell apoptosis (POTE E) and signal transcription (TXLNG)[12-15]. We do believe that informative molecules originating from tumor cells or their microenvironment may indeed be present in biological fluids and that their identification may lead to the discovery of potential new biomarkers. But, it is highly unlikely that a small and localized tumor will be able to modify the serum proteomic pattern to a degree that can be recognized by the proteomic technologies based on MS. The identification of these molecules will likely require ultrasensitive techniques, capable of measuring concentration ranges $10^{-12}-10^{-13} \mathrm{~mol} /$ liter or lower (far lower than those achieved by current MS). An alternative hypothesis for the observed differences in proteomic patterns in serum between different treatment sensitive patients may be the detection of high-abundance molecules that are not produced by the tumor cells but rather represent epiphenomena of tumor presence or treatment reaction. For example, it has been postulated by Diamondis et al. that at least some of the detected molecules represent acute-phase reactants that are released into the circulation by the liver and other organs[16]. It has been shown as early as 30-40 years ago that such molecules are not specific for the presence of any cancer, and for this reason they have not been used in clinical practice for cancer diagnosis or monitoring, although their concentrations may be elevated in serum of treatment sensitive/resistant patients.

Based on the second hypothesis, we elaborate on two potential candidate biomarkers, ApoA-1 and a1-AT. Given the flood of new targets identified as potential biomarkers, it would greatly strengthen the study to show subsequent validation of these two, especially as they are commercially available ELISA tests for them. ApoA-1 is the major protein component of high-concentration lipoprotein (HDL) and a key element of the reverse cholesterol transport pathway, a process that protects against the development of atherosclerosis[17]. Previous studies have reported the diagnostic value of ApoA-1 and proApolipoprotein A1 (the precursor of ApoA-1) in tumor diagnosis. Decreased levels of ApoA-1 were found in a variety of cancers[18-23], but pro-ApoA-1 increased in breast cancer[24]. Marchi et al found that pro-ApoA-1 significantly increased $(p<0.05)$ in lung cancer patients with brain metastases [25]. The identified proteins that we got have been validated in this experiment. Although the concentration of ApoA-1 in resistant group was lower than that in sensitive group, no significant difference between the two groups was found. a1-AT is one of the most important extra-cellular serine protease inhibitors. The major physiological role of a1-AT in the lung is to bind and inhibit elastase released from leucocytes in the lower respiratory tract, thereby preventing the destruction of lung tissue[26,27]. Elevation of a1-AT serum levels has been observed in the course of a large number of malignant diseases. Mean serum levels of a1-AT were found to be elevated in NSCLC patients and significantly correlated with the stage of cancer[28]. It was previously reported that the serum concentration of a1-AT increased with tumor growth and could be utilized following tumor resection as an indicator of relapse[29,30]. The prognostic significance of a1-AT expression in lung adenocarcinoma has been evaluated using immunohistochemistry; strongly a1-AT positive cases had a worse prognosis than weak-to-moderately a1-ATpositive or a1-AT-negative cases, suggesting that increased a1-AT expression in lung adenocarcinoma patients may be a prognostic indicator[31]. The level of $\alpha 1-\mathrm{AT}$ in resistant group was higher than that in sensitive group in our experiments $(p<0.05)$. So, our study confirmed that NSCLC patients with higher a1-AT level in serum before CRT may have a worse treatment outcome. In other words, serum a1-AT is a predictive biomarker for outcome of NSCLC patients treated with CRT.

The study still has some limitations. We do not have a blind test set of patients for verifying. Additionally, due to the lack of reproducibility, procedural bias, and virtually no independent confirmation, protein identification and detection of potential disease biomarkers in human serum are still big challenges for MS and bioinformatics analysis[32]. For example, the reproducibility of 2-DE profiles was very central to the key point. As variation in experimental procedures is a common source of variability in 2-DE patterns, 2-DE gel patterns were not easily reproducible between laboratories, making validation difficult. MS is a largely qualitative technique. Relationship between peak height and molecule abundance is not linear and could be very complex. Discriminating peaks identified by different investigators for the same disease are different. (Diamandis, EP. 2003)

In summary, the results presented here provide clues in identifying new serologic predictive biomarkers, demonstrate whether NSCLC patients could benefit from CRT or not, and might bear further investigation. Serum $\alpha 1$-AT was proved by our experiments as a predictive biomarker for outcome of NSCLC patients treated with CRT. Further rigorous testing in a prospective clinical trial setting can determine whether any candidate biomarker will have clinical utility regardless of its identification.

Acknowledgements: The authors are grateful to the National Center of Biomedical Analysis, China and professor Yazhou Cui of Shandong Academy of Medical Sciences for the technical guidance.

\section{References}

[1] MANEGOLD C, THATCHER N: Survival improvement in thoracic cancer: progress from the last decade and be- 
yond. Lung Cancer 2007; 57 Suppl 2: S3-5. http://dx.doi. org/10.1016/S0169-5002(07)70420-8

[2] JEMAL A, MURRAY T, WARD E, SAMUELS A, TIWARI RC et al: Cancer statistics, 2005. CA Cancer J Clin 2005; 55: 10-30. http://dx.doi.org/10.3322/canjclin.55.1.10

[3] ENGWEGEN JY, GAST MC, SCHELLENS JH, BEIJNEN JH: Clinical proteomics: searching for better tumour markers with SELDI-TOF mass spectrometry. Trends Pharmacol Sci 2006; 27: 251-259. http://dx.doi.org/10.1016/ j.tips.2006.03.003

[4] MOSLEY K, TAM FW, EDWARDS RJ, CROZIER J, PUSEY $\mathrm{CD}$ et al: Urinary proteomic profiles distinguish between active and inactive lupus nephritis. Rheumatology (Oxford) 2006; 45: 1497-1504. http://dx.doi.org/10.1093/rheumatology/kel351

[5] TOMOSUGI N, KITAGAWA K, TAKAHASHI N, SUGAI S, ISHIKAWA I: Diagnostic potential of tear proteomic patterns in Sjogren's syndrome. J Proteome Res 2005; 4: 820-825. http://dx.doi.org/10.1021/pr0497576

[6] GORG A, OBERMAIER C, BOGUTH G, HARDER A, SCHEIBE B et al: The current state of two-dimensional electrophoresis with immobilized $\mathrm{pH}$ gradients. Electrophoresis 2000; 21: 1037-1053. http://dx.doi.org/10.1002/(SICI)15222683(20000401)21:6<1037::AID-ELPS1037>3.0.CO; 2-V

[7] CORBETT JM, DUNN MJ, POSCH A, GORG A: Positional reproducibility of protein spots in two-dimensional polyacrylamide gel electrophoresis using immobilised $\mathrm{pH}$ gradient isoelectric focusing in the first dimension: an interlaboratory comparison. Electrophoresis 1994; 15: 1205-1211. http:// dx.doi.org/10.1002/elps.11501501182

[8] AEBERSOLD R, MANN M: Mass spectrometry-based proteomics. Nature 2003; 422: 198-207. http://dx.doi. org/10.1038/nature01511

[9] DIAMANDIS EP: Mass spectrometry as a diagnostic and a cancer biomarker discovery tool: opportunities and potential limitations. Mol Cell Proteomics 2004; 3: 367-378. http:// dx.doi.org/10.1074/mcp.R400007-MCP200

[10] XI L, JUNJIAN Z, YUMIN L, YUNWEN L, HONGBIN W: Serum biomarkers of vascular cognitive impairment evaluated by bead-based proteomic technology. Neurosci Lett 2009; 463: 6-11. http://dx.doi.org/10.1016/j.neulet.2009.07.056

[11] SALMON S, CHEN H, CHEN S, HERBST R, TSAO A et al: Classification by mass spectrometry can accurately and reliably predict outcome in patients with non-small cell lung cancer treated with erlotinib-containing regimen. J Thorac Oncol 2009; 4: 689-696. http://dx.doi.org/10.1097/ ITO.0b013e3181a526b3

[12] BERA TK, SAINT FLEUR A, LEE Y, KYDD A, HAHN Y et al: POTE paralogs are induced and differentially expressed in many cancers. Cancer Res 2006; 66: 52-56. http://dx.doi. org/10.1158/0008-5472.CAN-05-3014

[13] YU VW, GAUTHIER C, ST-AMNAUD R: Inhibition of ATF4 transcriptional activity by FIAT/gamma-taxilin modulates bone mass accrual. Ann N Y Acad Sci 2006; 1068: 131-142. http://dx.doi.org/10.1196/annals.1346.027

[14] HOTOKEZAKA Y, VAN LEYEN K, LO EH, BEATRIX B, KATAYAMA I et al: alphaNAC depletion as an initiator of ER stress-induced apoptosis in hypoxia. Cell Death Differ 2009; 16: 1505-1514. http://dx.doi.org/10.1038/cdd.2009.90

[15] KUMANISHI T, USUI H, ICHIKAWA T, NISHIYAMA A, KATAGIRI $\mathrm{T}$ et al: Human glial fibrillary acidic protein (GFAP): molecular cloning of the complete cDNA sequence and chromosomal localization (chromosome 17) of the GFAP gene. Acta Neuropathol 1992; 83: 569-578. http://dx.doi. org/10.1007/BF00299404

[16] DIAMANDIS, EP: Proteomic patterns in serum and identification of ovarian cancer. Lancet 2002; 359: 572-577. http://dx.doi.org/10.1016/S0140-6736(02)07746-2

[17] FIELDING CJ, FIELDING PE: Molecular physiology of reverse cholesterol transport. J Lipid Res 1995; 36: 211-228.

[18] KOZAK KR, SU F, WHITELEGGE JP, FAULL K, REDDY S et al: Characterization of serum biomarkers for detection of early stage ovarian cancer. Proteomics 2005; 5: 4589-4596. http://dx.doi.org/10.1002/pmic.200500093

[19] AI J, TAN Y, YING W, HONG Y, LIU S et al: Proteome analysis of hepatocellular carcinoma by laser capture microdissection. Proteomics 2006; 6: 538-546. http://dx.doi.org/10.1002/ pmic. 200500257

[20] ENGWEGEN JY, HELGASON HH, CATS A, HARRIS N, BONFRER JM et al: Identification of serum proteins discriminating colorectal cancer patients and healthy controls using surfaceenhanced laser desorption ionisation-time of flight mass spectrometry. World J Gastroenterol 2006; 12: 1536-1544.

[21] GOUFMAN EI, MOSHKOVSKII SA, TIKHONOVA OV, LOKHOV PG, ZGODA VG et al: Two-dimensional electrophoretic proteome study of serum thermostable fraction from patients with various tumor conditions. Biochemistry (Mosc) 2006; 71: 354-360. http://dx.doi. org/10.1134/S000629790604002X

[22] MOORE LE, FUNG ET, MCGUIRE M, RABKIN CC, MOLINARO A et al: Evaluation of apolipoprotein A1 and posttranslationally modified forms of transthyretin as biomarkers for ovarian cancer detection in an independent study population. Cancer Epidemiol Biomarkers Prev 2006; 15: 1641-1646. http://dx.doi.org/10.1158/1055-9965.EPI-05$\underline{0980}$

[23] EHMANN M, FELIX K, HARTMANN D, SCHNOLZER $M, N E E S M$ et al: Identification of potential markers for the detection of pancreatic cancer through comparative serum protein expression profiling. Pancreas 2007; 34: 205-214. http://dx.doi.org/10.1097/01.mpa.0000250128.57026.b2

[24] HUANG HL, STASYK T, MORANDELL S, DIEPLINGER $\mathrm{H}$, FALKENSAMMER G et al: Biomarker discovery in breast cancer serum using 2-D differential gel electrophoresis/ MALDI-TOF/TOF and data validation by routine clinical assays. Electrophoresis 2006; 27: 1641-1650. http://dx.doi. org/10.1002/elps.200500857

[25] MARCHI N, MAZZONE P, FAZIO V, MEKHAIL T, MASARYK T et al: ProApolipoprotein A1: a serum marker of brain metastases in lung cancer patients. Cancer 2008; 112: 1313-1324. http://dx.doi.org/10.1002/cncr.23314

[26] CRYSTAL RG: The alpha 1-antitrypsin gene and its deficiency states. Trends Genet 1989; 5: 411-417. http://dx.doi. org/10.1016/0168-9525(89)90200-X 
[27] SUN Z, YANG P: Role of imbalance between neutrophil elastase and alpha 1-antitrypsin in cancer development and progression. Lancet Oncol 2004; 5: 182-190. http://dx.doi. org/10.1016/S1470-2045(04)01414-7

[28] EL-AKAWIZJ, ABU-AWARDAM, SHARARA AM, KHADER Y: The importance of alpha-1 antitrypsin (alpha1-AT) and neopterin serum levels in the evaluation of non-small cell lung and prostate cancer patients. Neuro Endocrinol Lett 2010; 31: 113-116.

[29] HOMOLKA J, VOSLAROVA Z, MALBOHAN I: [Significance of alpha-1-antitrypsin and alpha-2-pregnancy-associated glycoprotein in the serum of patients with bronchial carcinoma]. Z Erkr Atmungsorgane 1987; 169: 38-43.
[30] DI MARTINO G, IANNUCCI F, BIZZARRO A, IACONO G: [Association of serum tumor markers in solid neoplasms (CEA, ferritin, alpha 1-antitrypsin, parathormone and calcitonin)]. Boll Ist Sieroter Milan 1982; 61: 411-422.

[31] HIGASHIYAMA M, DOI O, KODAMA K, YOKOUCHI H, TATEISHI R: An evaluation of the prognostic significance of alpha-1-antitrypsin expression in adenocarcinomas of the lung: an immunohistochemical analysis. Br J Cancer 1992; 65: 300-302. http://dx.doi.org/10.1038/bjc.1992.60

[32] FINDEISEN P, NEUMAIER M: Mass spectrometry based proteomics profiling as diagnostic tool in oncology: current status and future perspective. Clin Chem Lab Med 2009; 47: 666-684. http://dx.doi.org/10.1515/CCLM.2009.159 